\title{
Weighing patients in Scottish critical care units: weighed down by Inaccuracy?
}

\author{
C. Hurnauth ${ }^{1}$ and M. Mcdougall ${ }^{2}$ \\ ${ }^{1} I C U$ St. John's Hospital at Howden, Livingston, EH54 6PP, UK and ${ }^{2} I C U$ Queen Margaret Hospital, Dunfermline, \\ KY12 OSU, UK
}

The accurate determination of height and weight is an essential component of not only nutritional screening, but is also required for cardiac output studies, and is necessary to monitor fluid balance and calculate drug dosages. An accurate height is relatively easy to obtain. Weight is more problematic with Hendershot et al. ${ }^{(1)}$ reporting significant inaccuracies between patient-reported and relativereported weight. Estimation of weight by experienced healthcare providers has also been shown to be grossly inaccurate ${ }^{(2)}$.

Quality Improvement Scotland (QIS) Standards ${ }^{(3)}$ and the National Institute of Clinical Excellence (NICE) guidelines on Nutritional Support in Adults ${ }^{(4)}$ require that all patients undergo nutritional screening, for which the determination of BMI is essential. The determination of an accurate weight is the major limiting factor in achieving this goal. The widespread adoption of the Malnutrition Universal Screening Tool (MUST) ${ }^{(5)}$ in acute hospital wards across NHS Scotland has led to an increase in the number of patients being weighed on admission, but critical care units are lagging behind in the calculation of BMI and nutritional status.

The process of weighing a critical care patient presents a unique series of challenges to healthcare staff. The safe use of a hoist ideally requires a stable patient and several staff members; many units have expressed health and safety concerns regarding this process. Weigh beds are expensive and not widely used. Many critical care units therefore depend on inaccurate estimates of weight.

A telephone survey of critical care units across Scotland was carried out in 2008-9 to determine current practice. Replies from 14 NHS Trusts representing 27 critical care units were obtained. The majority of these units accept both Level 2 and Level 3 patients.

\begin{tabular}{llrl}
\hline Results & Yes & No & \\
\hline Do you weigh on admission? & 1 & 13 & \\
Do you weigh regularly? & 1 (weekly) & 9 & \\
Do you weigh on discharge? & 1 & 13 & 4 weigh for cardiac output studies only \\
Do you use nutritional screening? & 5 (MUST) & 8 & \\
\hline
\end{tabular}

\begin{tabular}{|c|c|c|c|c|c|}
\hline & Stadiometer & Tape measure & Never measure & Estimate by staff & Relatives/notes/Ulnar length \\
\hline How do you measure height? & $\begin{array}{c}1 \\
\text { Hoist }\end{array}$ & $\begin{array}{c}\quad 5 \\
\text { Bed scales }\end{array}$ & $\begin{array}{c}8 \\
\text { Never measure }\end{array}$ & $\begin{array}{c}5 \\
\text { Estimate by staff }\end{array}$ & $\begin{array}{c}3 \\
\text { Information from relatives/notes }\end{array}$ \\
\hline How do you weigh? & 4 (3 rarely used) & 1 (rarely used) & 9 & 13 & 13 \\
\hline
\end{tabular}

It is clear from the results that obtaining accurate weights in Scottish critical care units has a low priority and that this may have implications for many aspects of patient care. The Scottish Intensive Care Society Nutrition Group has discussed the results and is now focusing on improving the situation. Many units have now begun to take action by purchasing bed scales or weigh beds and introducing nutritional screening.

1. Hendershot K, Robinson L, Rowland J et al. (2006) J Am Coll Surgeons, 203, 887-893.

2. Bloomfield R, Steel E, MacLennan G et al. (2006) Crit Care Med 34(8), 2153-2159.

3. NHS Quality Improvement Scotland (2003) Food Fluid and Nutritional Care in Hospitals (Clinical Standards).

4. National Institute for Clinical Excellence (2008) CG32: Nutrition Support for Adults.

5. Malnutrition Advisory Group (2000) MAG guidelines for detection and management of malnutrition. Maidenhead: British Association for Parenteral and Enteral Nutrition (BAPEN). 